International Journal of Engineering \& Technology, $7(2.33)(2018) 653-656$
International Journal of Engineering \& Technology
WPC
Website: www.sciencepubco.com/index.php/IJET
Research paper

\title{
Integrated proposition on tracking environment
}

\author{
S.Karunya $^{1}$, Dr. K. Kalaiselvi ${ }^{2}$ \\ ${ }^{1}$ Research Scholar \\ ${ }^{2}$ Associate Professor \& Head School of Computing Sciences Department of Computer Science Vels Institute of Science, Technology \\ \& Advanced Studies, Chennai-600117, India \\ *Corresponding author E-mail: karunya.anandhan@gmail.com
}

\begin{abstract}
In current scenario, security level for an individual lies on a question mark.To overcome all situations based on safety. To provide a proper link to access things near us following header are used, they are GPS, GSM and GPRS. These systems help to track people on an individual basis which prevents the risk of kidnapping and other crimes happen to the people who depend on integrated proposition. This proposition monitors the day to day happening of the user and provides the results to receiver of the person which consists of parents, guardian, local police station and others who access the integrated tracking, while they check the panic button.
\end{abstract}

Keywords: GPRS; GPS; GSM; Integrated Proposition; Microphone \& Speaker.

\section{Introduction}

In recent times, there is an increased rate of women and children (girls) getting kidnapped and abducted by more number. Doing assault on women also got increased comparing to previous ratio. Pending cases are in more numbers eventually how many numbers are not encountered in such cases, which are unaware. To avoid such issues happen to both women $\&$ children and to prevent them from such happenings. A proper system to be initiated which helps in prevention as well as to protect them.

This system helps to monitor the user in the front side and alert the people in the receiver side using various technologies in-built in the integrated proposition. Using this proposition, a person would be sequentially tracked by the other person through GPS and GSM. Report of this update will be communicated as message and call from the user side by GSM/GPRS. It also covers the voice recognition of both victim and offender at the crucial time. In crucial time the victim (women/children) will check the panic button, immediately the alert will be passed on to the receiver end person. After the alert received the receiver end person will take necessary action to recover the women or children who are struck up in offender place. Block Diagram

Built-in embedded system

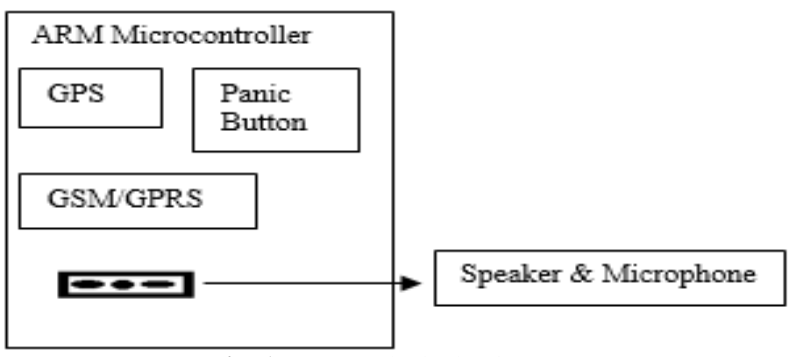

Fig. 1: Proposed Block Diagram.

\section{Related work}

According to A.Santhiya, Android Based women tracking system using GPS and GSM [1] which helps in tracking women by GPS and GSM using mobile application where it also acts as a server for the overall work.

\subsection{Main application}

This application sort out the location values of GPS and helps to send message and call through GSM.

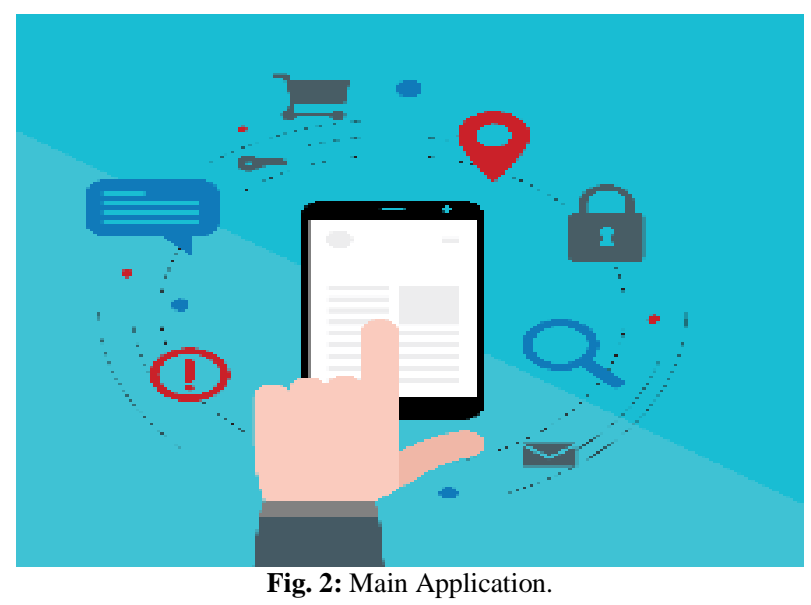

According to Shahid A Bangali, Real Time School Bus Tracking System with Biometrics, GPS and GPRS using ARM Controller[2] where it include GPS to track the location and GPRS to send voice call by recordings with the fingerprint of the children boarding bus.

\subsection{Biometrics}


Biometrics fingerprint is taken from children for synchronization while boarding the bus, from that point their tracking process will be initiated using GPS and GPRS. Using this technique the children who board the bus which proper recognition are tracked separate separately by their fingerprint.

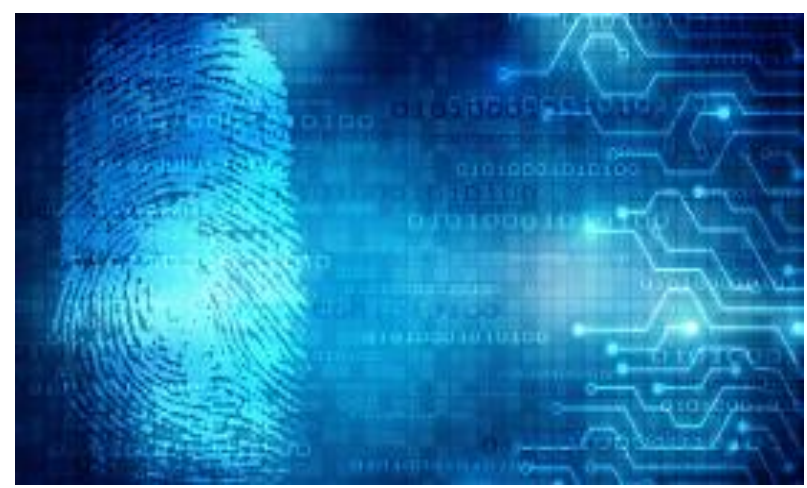

Fig. 3: Biometrics.

According to Sumit S. Dukare, Vehicle Tracking, Monitoring and Alerting System: A Review[3] which monitors vehicle using a separate server.

\subsection{Servers}

These servers receive and store the data sequentially from the user for the review of receiver end.

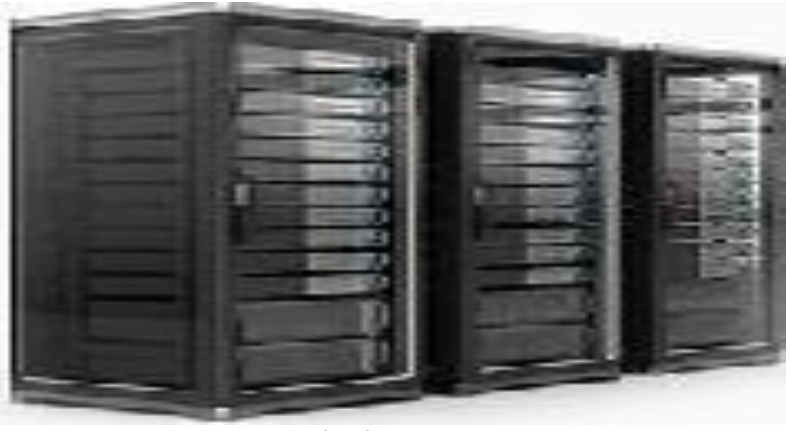

Fig. 4: Servers.

According to B.Hari Kumar, Vehicle Monitoring and Tracking System using GPS and GSM Technologies [4].

\subsection{Sensor on vehicle}

This sensor is used to sense the vehicle location and also prevent the vehicle from theft.

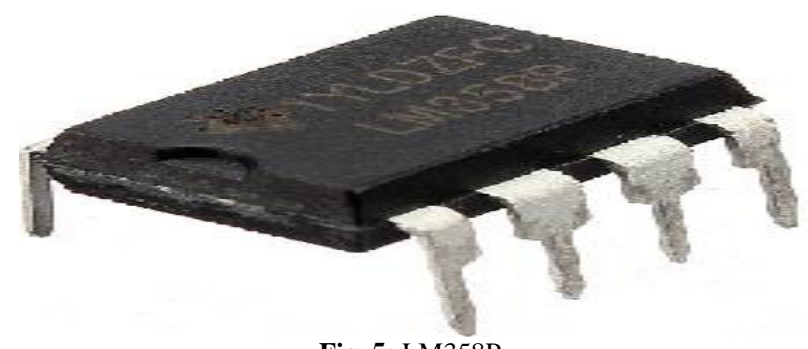

Fig. 5: LM358P

According to Abhishek S.Parab, Implementation of Home Security System using GSM module and Microcontroller [5].

\subsection{Magnet \& relay}

These magnet $\&$ relay are pasted to the door to sense the stranger who tries to open the door. In case anyone opens the door automatically the alert will be send to house owner mobile number as message.

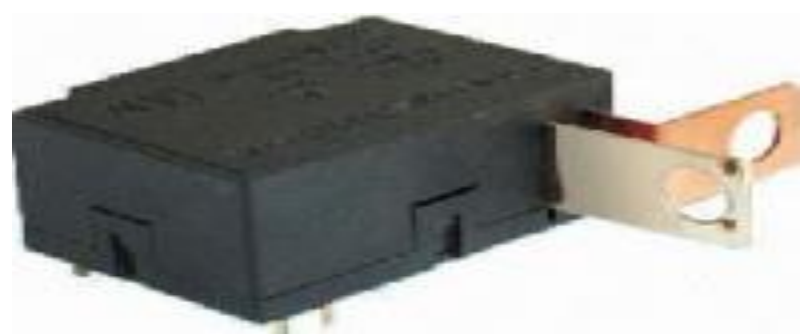

Fig. 6: Magnet and Relay.

Hazza Alshamisi, Real Time GPS Vehicle Tracking System [6] would track vehicle using GPS location values.

Miss.Trupti R.Chandhari, children tracking system using voice recognition [7] this system includes GPS, GSM and Voice Board to track children on their school, home and where ever they move.

Avein J. Al-Assady, A Proposed Model for Human Securing using GPS [8] would check the pulse of the user and report the status to the receiver end.

Rita H.Pawade, Android Based Child Tracking System [9] will track the children in a regular basis using GPS and GSM.

P.Madhu Bala S.Sivaraman," GPS Based Bus Tracking System [10] provides bus arrival time prediction system using GPS,SMS and RFID.

Priti Jadhav1, Kajal Ingale1, Shifa Asari1, Prof. Kalidas Bhawale," Student Tracking System using GSM and GPS Technology [11] Track the student and prevent them from kidnapping using GSM and GPS.

Geetha Pratyusha Miriyala, Smart Intelligent, Security System for women [12] This system includes two device one is wrist band and other one is spectacles. Wrist band is enabled with pressure switch spectacles is enabled with live video and tear gas Mechanism.

Maheswari V.Chandrawar, Anti-Theft security system using GSM, GPS, RFID technology based on ARM 7[13] This work monitors the car from theft and In case of any wrong attempt of opening the car, message will be sent to the owner mobile.

Sameer Darekar, Tracking System using GPS, GSM: Practical Approach [14] This System tracks cars using GPS, GSM and stores the data in Server.

\section{Proposed system}

Majorly this system involves on tracking proposition which helps people to prevent themselves on the basis of safety and security. These integrated environments manage the small circuits which are in synchronized proposition form. To sort the major advantages of security, it is inbuilt with GPS, GSM\& GPRS with integrated microphone to track the voice of the user in the front side. This helps to emphasize the sound of user and alter the other side person on the current state of the user.GPS tracks the location of the user where GSM communicate with the receiver end person through message and GPRS will give a call with voice extracts of the user through microphone. A panic button also inserted in this proposition to check at the risky time of the user. These technologies are inbuilt integrated proposition which is carried by the user.

\subsection{GPS}

GPS (Global Positioning System) detects the location values of the user side and update the value in the receiver side. This technology consists of longitude and latitude values through satellite and covers the person where they are carrying the appropriate integrated proposition. 


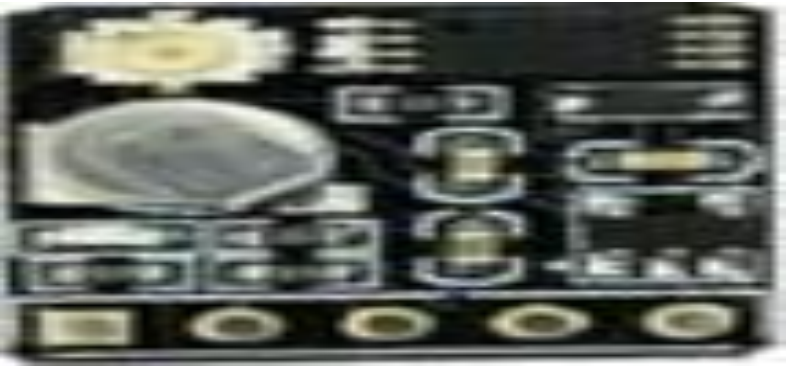

Fig. 7: GPS.

\subsection{GSM/GPRS}

These technologies used to send adequate message and call to the receiver side, when the panic button is checked.GSM would send the location values and location to the receiver end while GPRS would give a missed call to the receiver simultaneously.

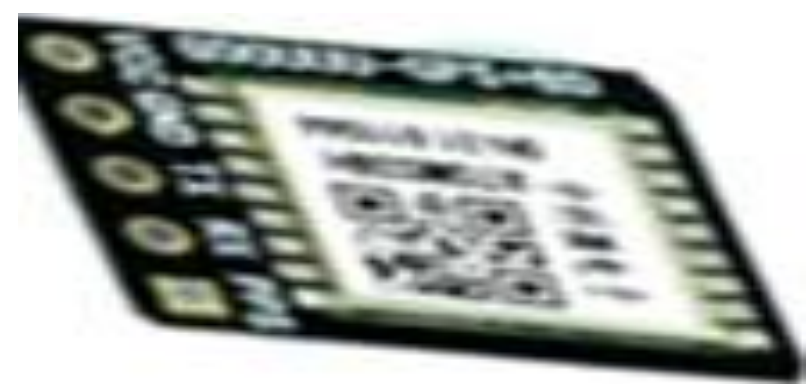

Fig. 8: GSM/GPRS.

\subsection{Panic button}

If this button is checked, automatically it will alert the receiver side from the front side

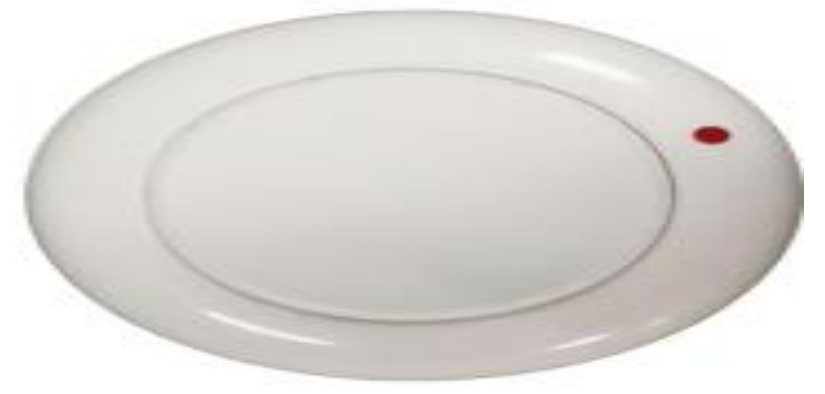

Fig. 9: Panic Button.

\section{Results \& discussion}

Integrated proposition are synchronized together to form a structured device by an embedded anklet .This proposition helps to build product which work with numerous functions and technologies. Women or children would check on the panic button, when they are adobe to a crucial point or when they are been kidnapped by a stranger or some others who attempt rape assault on them.

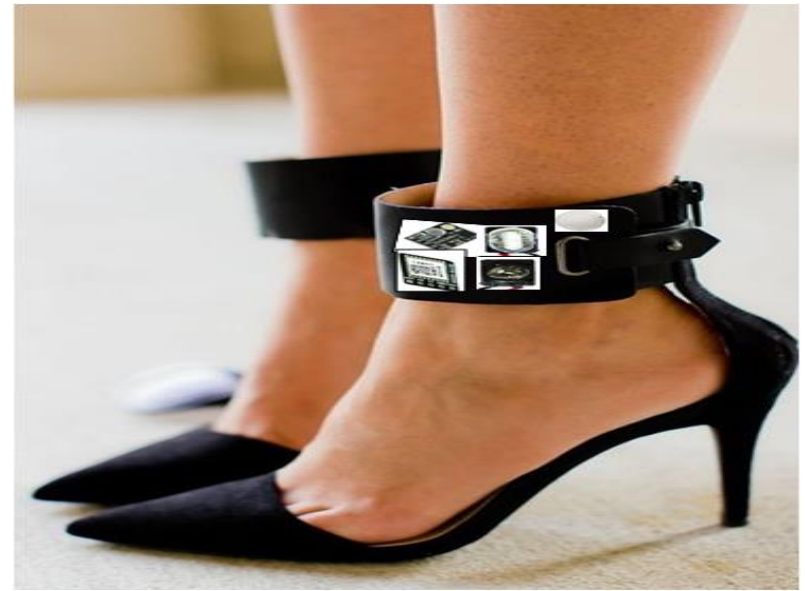

Fig. 10: Integrated Proposition of Proposed System.

\section{Conclusion}

Our Proposed system relies on compactness and provides the accurate values of location where the front end person moves by his/her way. This system alerts the receiver by checking panic button to avoid risk immediately. It also decreases the big circuits by optimization and overcomes the disadvantages of the existing system. Measures are accurate and easy to monitor the user from other side. Overall this system works properly without any discrepancy. Future enhancement would be providing more feature to the proposition and increase the compactness which has to be unknown by the stranger.

\section{References}

[1] A.Santhiya, B.Hari Prakash, J.Mithilaesh, Dr.K.Valarmathi (2016),"Android Based women tracking system using GPS and GSM", International Journal for Research in Applied Science \& Engineering Technology (IJRASET), Vol4 (4), pp.2321-9653.

[2] Shahid A Bangali, Dr.S.K.Shah (2015), "Real Time School Bus Tracking system with Biometrics, GPS and GPRS using ARM Controller", International Journal of Advanced Research in Electrical, Electronics and Instrumentation Engineering Vol. 4, Issue 8,pp.7043-7027.

[3] Sumit S. Dukare,Dattatray A. Patil,Kantilal P. Rane (2015), "Vehicle Tracking, Monitoring and Alerting System: A Review",International Journal of Computer Applications Volume 119 - No.10,pp.39-44.

[4] B.Hari Kumar, Syeda Fathima Tehseen, S.Thanveer, Guntha Vamshi Krishna, Syed Mohisin Akram (2016)," Vehicle Monitoring and Tracking System using GPS and GSM Technologies",International Research Journal of Engineering and Technology (IRJET), Vol. 3(4),pp.2395-0072.

[5] Abhishek S.Parab, AmolJoglekar (2015), "Implementation of Home Security System using GSM module and Microcontroller", International Journal of Computer Science and Information Technologies, Vol. 6(3), pp.2950-2953.

[6] Hazza Alshamisi,Veton Kepuska (2017)," Real Time GPS Vehicle Tracking System", International Journal of Advanced Research inElectronicsandCommunicationEngineering(IJARECE), Vol.6(3), pp.2278-909X

[7] Miss.Trupti R.Chandhari, Dr.A.J.Patil (2017),"'children tracking system using voice recognition", Global Journal of Advanced Engineering Technologies, Vol.6 Issue 1, pp.2277-6370.

[8] Avein J. Al-Assady,Bahaa T. Shabana, HazemM.El-Bakry (2015), “A Proposed Model for Human Securing using GPS”, International Journal of Electronics Communications and Computer Engineering, Volume 6, Issue 6, pp.2278-4209.

[9] RitaH.Pawade, Dr.Arun \& N. Gaiwad Savitribai Phule (2015),"Android Based Child Tracking System", International Journal ofScience, Engineering and Technology Research (IJSETR), Vol.4, Issue6, pp.2278-7798.

[10] P.Madhu Bala S.Sivaraman (2017)," GPS Based Bus Tracking System ", International journal for electronics and communication engineering, pp.2348-8549. 
[11] Priti Jadhav1, Kajal Ingale1, Shifa Asari1, Prof. Kalidas Bhawale (2017)," Student Tracking System using GSM and GPS Technology", International Journal of Innovative Research in Computer and Communication Engineering, Vol.5 Issue 3,pp.2320-9801.

[12] Geetha Pratyusha Miriyala , P.V.V.N.D.P.Sunil, Ramya Sree Yadalapalli, Vasantha rama Lakshmi pasam, Tejaswri Kondapalli, Anusha Miriyala (2016)," Smart Intelligent, Security System for women", International Journal of Electronics and Communication Engineering \& Technology ,Vol.7 Issue 2,pp. 0976-6464.

[13] Maheswari V.Chandrawar, Miss.Shital Y.Gaikwad (2013)," AntiTheft security system using GSM, GPS, and RFID technology based on ARM 7", International Journal of Engineering Research \& Technology (IJERT), Vol.2 Issue 9, pp. 2278-0181.

[14] Sameer Darekar, Atul Chikane, Rutujit Diwate, Amol Deshmukh, Prof.Archana Shinde (2012)," Tracking System using GPS, GSM :Practical Approach", International Journal of Scientific \& Engineering Research ,Vol.3, Issue 5,pp. 2229-5518. 